\title{
Fetichismo y revolución en la teoría marxista contemporánea: una evaluación crítica de la Neue Marx-Lektüre y el Marxismo Abierto en clave metodológica
}

\author{
Fetishism and Revolution in contemporary Marxist theory: a critical \\ methodological assessment of the Neue Marx-Lektüre and Open Marxism
}

Guido Starosta*

\begin{abstract}
Resumen: El artículo examina una serie de aportes recientes a la lectura de El capital que hacen eje en su determinación como una investigación dialéctica de las formas fetichizadas de mediación social en el capitalismo. Más específicamente, se aborda la Neue Marx-Lektüre y el Marxismo Abierto. Se argumenta que los límites de estas perspectivas emergen en la forma en que conciben las determinaciones de la subjetividad revolucionaria, la cual no logran fundar en el despliegue inmanente de las formas capitalistas de mediación social.
\end{abstract}

Palabras Clave: El Capital; Revolución; Dialéctica; Neue Marx-Lektüre; Marxismo Abierto

\begin{abstract}
This article examines a series of recent contributions to the reading of Capital that stress its determination as a dialectical investigation of fetishised forms of social mediation in capitalist society. Specifically, the article focuses on the Neue Marx-Lektüre and Open Marxism. The article argues that the limits of these perspectives become apparent when it comes to uncover the determinations of revolutionary subjectivity, which they fail to ground in the immanent unfolding of capitalist forms of social mediation.
\end{abstract}

Keywords: Capital; Fetishism; Revolution; Dialectics; Neue Marx-Lektüre; Open Marxism

Recibido: 09/06/2017

Aceptado: 30/07/2017

\footnotetext{
* Argentino, Doctor en Sociología por la Universidad de Warwick (Reino Unido), Profesor Titular de la Universidad Nacional de Quilmes (UNQ) e Investigador Adjunto del Consejo Nacional de Investigaciones Científicas y Técnicas. CoDirector del Programa de Investigación UNQ "Acumulación, dominación y lucha de clases en la Argentina contemporánea. 1989-2011 (PUNQ 1017/11)" (2015-2019) e Investigador Responsable del Proyecto de Investigación Científica y Tecnológica (PICT 3577/2014), "La acumulación del capital en la posconvertibilidad" (2016-2019), Fondo para la Investigación Científica y Tecnológica, Ministerio de Ciencia, Tecnología e Innovación Productiva. Guido.Starosta@unq.edu.ar
} 


\section{Introducción}

El propósito de este capítulo es examinar una serie de contribuciones recientes a la crítica marxiana de la economía política que enfatizan su determinación específica como una investigación dialéctica sobre las formas fetichizadas o materializadas de mediación social. En concreto, nos proponemos aquí abordar críticamente los aportes de la llamada Neue Marx-Lektüre, así como a la producción, más difundida en las últimas décadas, de autores asociados a la corriente del llamado Marxismo abierto.

La Neue Marx-Lektüre es una corriente intelectual surgida en Alemania Occidental en la segunda mitad de la década de 1960, cuyas contribuciones originales principales pueden encontrarse en las obras de Helmut Reichelt y Hans-Georg Backhaus, en las cuales focalizaremos la presente discusión ${ }^{1}$. Esta lectura reconstructiva de la crítica marxiana de la economía política se desarrolló tanto bajo el influjo positivo de ciertas temáticas clave de la Escuela de Frankfurt (en particular de las ideas del último Adorno, pero también de las relecturas de Marx por parte de autores de "segunda generación" del círculo frankfurtiano tales como Alfred Schmidt e Iring Fetscher), como en oposición las lecturas tradicionales de la obra de Marx prevalecientes en Alemania en esa época, las cuales derivaban de las interpretaciones del marxismo-leninismo y la socialdemocracia ${ }^{2}$. Más en concreto, y tal como señala Ingo Elbe, son varias las ideas rectoras de dicha lectura tradicional que las intervenciones de la Neue Marx-Lektüre pusieron en cuestión, entre las cuales, a nuestro juicio, se destacan las siguientes. ${ }^{3}$ En primer lugar, se cuestionaba la interpretación "sustancialista" o Ricardiana de la teoría del valor de Marx, poniendo de relieve, en contraste, la investigación sobre la forma-valor, esto es, sobre la historicidad y peculiaridad de la objetividad de valor como forma social específica (y, de allí, su conexión inmanente y necesaria con la forma-dinero, soslayada notoriamente en las lecturas tradicionales). En términos más generales, esto conducía a concebir a la obra de madurez de Marx no como una teoría económica alternativa sino como una crítica de la economía política, es decir, como una ciencia de la constitución social o génesis de las formas económicas del capitalismo en su totalidad y articulación interna (o un análisis crítico de las

\footnotetext{
${ }^{1}$ Helmut Reichelt, Sobre a Estrutura Lógica do Conceito de Capital em Karl Marx, Campinas, Editora Unicamp, 2009; Hans-Georg Backhaus, Dialettica della Forma di Valore. Elementi critici per la riconstruzione della teoría marxiana del valore, Roma, Editori Riuniti, 2009. En este sentido, cabe reslatar que con las intervenciones de Reichelt y Backhaus como una suerte de puntapié inicial, la Neue Marx-Lektüre se ha desarrollado luego en múltiples y variadas direcciones mediante los aportes de nuevas generaciones de autores, los cuales, desafortunadamente, no han sido mayormente traducidos del alemán, con la excepción de algunos trabajos de Michael Heinrich. Ver Michael Heinrich, Crítica de la Economía Política. Una introducción a El Capital de Marx, Madrid, Escobar y Mayo, 2008; Michael Heinrich, ¿Cómo leer El Capital de Marx? Indicaciones de lectura y comentario del comienzo de El Capital, Madrid, Escobar y Mayo, 2011. De todas maneras, puede encontrarse una muy útil y concisa exposición de la riqueza y complejidad de los desarrollos y debates posteriores de esta corriente hasta tiempos recientes, en la visión panorámica ofrecida por Jan Hoff, Marx Worlwide: On the Development of the International Discourse on Marx since 1965, Leiden, Brill, 2016, 74-92.

${ }^{2}$ Para una contextualización intelectual e histórica de la Neue Marx-Lektüre, ver Ingo Elbe, "Between Marx, Marxism and Marxisms. Ways of Reading Marx's Theory", Viewpoint Magazine - Investigations in Contemporary Politics, www.viewpointmag.com, 21 de octubre de 2013; Endnotes, "Communisation and Value-Form Theory", 2, 2010, 68-105; Riccardo Bellofiore y Tommaso Redolfi Riva "The Neue Marx-Lekture. Putting the critique of political economy back into the critique of society", Radical Philosophy, 189, 2015, 24-36.

${ }^{3}$ Elbe, op. cit.
} 
"determinaciones de forma" de la sociedad capitalista). En segundo lugar, y a nivel metodológico, se rechazaba la ortodoxia derivada de Engels que leía la exposición de $E l$ capital en términos del llamado enfoque lógico-histórico, el cual considera que la secuencia de determinaciones presentada en El capital correspondería a la evolución efectiva de la sociedad humana, de modo que la sección primera sobre la mercancía y el dinero constituirían la representación analítica de una sociedad precapitalista de productores mercantiles realmente existente en la historia. En contraposición, los autores de la Neue Marx-Lektüre se embarcaron en una reconsideración radical del método de la crítica de la economía política, abordándolo como una dialéctica conceptual o sistemática de las categorías económicas, inspirada, a grandes rasgos y de forma idiosincrática, en la forma de exposición de la Ciencia de la lógica de Hegel. Así, las determinaciones más generales expuestas en la sección primera de El Capital dejaban de mirarse como simples existencias históricas que precedían a la sociedad capitalista, y pasaban a concebirse como formas abstractas o momentos internos del capital como totalidad concreta ${ }^{4}$. Finalmente, y en la coyuntura de las revueltas estudiantiles universitarias de esos tiempos, estas nuevas lecturas de la crítica de la economía política se distanciaban de modo explícito de todo intento de establecer un vínculo directo con la inmediatez de las luchas de las organizaciones políticas tradicionales del movimiento obrero, permaneciendo en general confinados a la actividad académica.

En cuanto al Marxismo abierto, en gran medida comparte estos rasgos distintivos que caracterizan a la Neue Marx-Lektüre, si bien se ha desarrollado en un contexto intelectual, histórico y geográfico diferente ${ }^{5}$. Así, el surgimiento de esta corriente marxista puede rastrearse al mundo académico anglosajón hacia fines de la década de 1980 y comienzos de los años 90, como reacción crítica a las derivaciones del marxismo estructuralista de raigambre althusseriano en la forma de la Teoría de la regulación. En términos de coyuntura política, se trataba del período de ascenso y consolidación de la Nueva Derecha y, como la otra cara de la moneda, de retroceso y derrota de las radicalizadas luchas obreras acaecidas en la década de 1970. En este marco, emergen entonces intensos debates sobre el surgimiento y las características de un nuevo modo de acumulación del capital posfordista, lo cual era presentado en muchas de estas discusiones como el resultado inevitable e irrefrenable de las leyes objetivas del desarrollo capitalista, y frente al cual no cabría más que adaptarse pasivamente de la manera más progresiva posible, mediante un restablecimiento de una versión del reformismo keynesiano aggiornado para la era de la revolución microelectrónica. Frente a lo que se percibía como el carácter "cerrado" de estos posicionamientos marxistas respecto del proceso de crisis y reestructuración capitalista, el programa de investigación del Marxismo abierto apuntaba justamente a la "apertura" de las categorías de la crítica de la economía política (tanto en la

\footnotetext{
${ }^{4}$ Respecto de esta cuestión en particular, cabe resaltar la importancia que muchos de estos autores le dieron a los Grundrisse, incluso prefiriéndolo, por un supuesto mayor rigor metodológico, por sobre El capital, el cual era visto como involucrando una "popularización" del método dialéctico.

${ }^{5}$ Werner Bonefeld, Richard Gunn y Kosmas Psychopedis (eds.), Open Marxism, vol. 1: Dialectics and History, London, Pluto Press, 1992a; Werner Bonefeld, Richard Gunn y Kosmas Psychopedis K. (eds.), Open Marxism - vol. 2: Theory and Practice, London, Pluto Press, 1992b; Werner Bonefeld, Richard Gunn y Kosmas Psychopedis (eds.) 1995, Open Marxism - vol. 3: Emancipating Marx, London, Pluto Press, 1995.
} 
teoría como en la práctica), al entenderlas como formas fetichizadas de existencia del antagonismo de clases, siendo en este punto donde no sólo tomaban distancia de los enfoques tributarios del estructuralismo (o, asimismo, de la ortodoxia del marxismoleninismo), sino incluso de las figuras fundacionales de la Neue Marx-Lektüre. En este sentido, en la discusión del Marxismo abierto nos detendremos en particular en el trabajo de Werner Bonefeld, quien, al tiempo que de manera explícita se identifica con el legado intelectual de Backhaus y Reichelt, enmarca las contribuciones científicas de estos últimos en un terreno más deliberadamente vinculado a la acción política ${ }^{6}$. Asimismo, discutiremos también el trabajo de Richard Gunn, otro autor fundacional de este enfoque, y quien quizás más haya aportado a las dimensiones metodológicas del mismo.

A nuestro juicio, quizás el aspecto más interesante de todos estos trabajos es que avanzan en poner de relieve las potencialidades de la crítica de la economía política, no sólo para la comprensión de las formas de objetividad social fetichizada del capitalismo, sino para comprender las formas de subjetividad del individuo moderno. En efecto, a grandes rasgos, estos enfoques comparten la idea, acertada a nuestro modo de ver, de que la determinación más simple de la subjetividad humana en el modo de producción capitalista es su existencia enajenada como personificación de categorías económicas. Sin embargo, argumentaremos que los límites de estas perspectivas se evidencian cuando se trata de avanzar sobre los fundamentos de la forma de subjetividad que porta la potencia inmanente de trascender la enajenación capitalista, es decir, cuando se trata de sacar a la luz las determinaciones del sujeto revolucionario.

En primer lugar, se desarrolla una discusión crítica pormenorizada de la Neue MarxLektüre y del Marxismo abierto. En términos sustantivos, se sostiene que estos autores fallan a la hora de fundar la emergencia de la subjetividad revolucionaria en el despliegue inmanente de las formas de mediación social capitalistas. En el caso de los primeros, por dejar a la problemática del sujeto revolucionario fuera del objeto de la crítica de la economía política. En el caso de los segundos, y a pesar de sus intentos deliberados por trascender toda exterioridad entre la subjetividad humana y el capital, por fundar las potencias revolucionarias de la clase obrera por fuera de su existencia enajenada como atributo de la relación social general objetivada, esto es, más allá de su determinación genérica como personificación de categorías económicas, en una abstracta humanidad carente de determinación social.

Asimismo, el artículo aborda dicha crítica de la Neue Marx-Lektüre y del Marxismo abierto en clave metodológica. De este modo, se muestra que tales limitaciones sustantivas van de la mano con una concepción inadecuada del método científico-crítico necesario para descubrir las determinaciones del sujeto revolucionario de modo inmanente. En efecto, para estos autores el método crítico marxiano subyacente al descubrimiento de la praxis revolucionaria se reduce al movimiento analítico de la reductio ad hominem, por medio del cual se rastrea el origen humano de las categorías económicas. El aspecto genético o sintético del método dialéctico es relegado así al papel de explicar la constitución social de las formas de objetividad de la sociedad capitalista y, en el mejor de los casos, de las formas de subjetividad que portan la reproducción de las primeras. Pero, desde estas

\footnotetext{
${ }^{6}$ Werner Bonefeld, Critical Theory and the Critique of Political Economy, London, Bloomsbury, 2014.
} 
perspectivas, dicho segundo momento de la investigación dialéctica nada tiene para aportar respecto de la comprensión del fundamento de la subjetividad revolucionaria.

En contraste con estas perspectivas, este artículo desarrolla un enfoque alternativo inspirado en los aportes fundacionales de Juan Iñigo Carrera ${ }^{7}$ que, en tanto apunta a dar cuenta de las potencias revolucionarias de la clase obrera de modo inmanente a su determinación plena como personificación del movimiento del capital total de la sociedad, se diferencia de los arriba reseñados por las siguiente dos dimensiones metodológicas centrales. En primer lugar, se demuestra que en tanto la subjetividad revolucionaria es una 'unidad de múltiples determinaciones', su fundamento no puede ser encontrado al 'nivel de abstracción' del fetichismo de la mercancía, tal como se sigue de modo implícito de la Neue Marx-Lektüre y el Marxismo abierto. En segundo lugar, y como consecuencia de lo anterior, se argumenta que el momento crítico del método dialéctico marxiano no consiste solo en la reductio ad hominem. Esta última es, ciertamente, la perspectiva en lo esencial analítica y de inspiración feuerbachiana desplegada por Marx en textos de 'juventud' como los Manuscritos de 1844. Sin embargo, el artículo sostiene que tal perspectiva se encuentra superada en El capital (y también de modo rudimentario, pero necesariamente complementario, en los Grundrisse y la Contribución a la crítica de la economía política), donde el descubrimiento inmanente de las potencias revolucionarias de la clase obrera surge del despliegue sintético de la totalidad de las determinaciones del capital en tanto sujeto enajenado del movimiento de la sociedad moderna, con punto de partida en su expresión más simple en la forma-mercancía. En este punto, nótese que no se trata de la producción histórica de condiciones objetivas exteriores a la subjetividad, lo cual fundaría una abstracta posibilidad de superación del capital. Más bien, se trata del desarrollo del contenido material inmanente, determinado por el propio capital, que necesariamente asume la forma de la acción política revolucionaria de la clase obrera. Dicho contenido, se argumentará, pasa por la transformación de los atributos productivos del obrero colectivo según una tendencia determinada por la plenitud de la subsunción real del trabajo en el capital: los órganos individuales de éste devienen sujetos productivos universales capaces de organizar de manera plenamente consciente su proceso de vida social. Como veremos, ésta es la determinación material inmanente que subyace a la subjetividad política revolucionaria del proletariado.

\section{Método y crítica-práctica de la Neue Marx-Lektüre al Marxismo Abierto}

\section{La Neue Marx-Lektüre de Backhaus y Reichelt}

Señalábamos recién que las perspectivas asociadas tanto a la Neue Marx-Lektüre como a su recepción más política en el mundo angloparlante por parte del Marxismo abierto, comparten una concepción particular del método y sentido de la crítica marxiana del fetichismo de las formas de mediación social capitalista. En efecto, al reducir el momento crítico de la investigación marxiana sobre el fetichismo de la mercancía al mero

\footnotetext{
${ }^{7}$ Juan Iñigo Carrera, Conocer el capital hoy. Usar críticamente El Capital, Buenos Aires, Imago Mundi, 2007; Juan Iñigo Carrera, El Capital: Razón Histórica, Sujeto Revolucionario y Conciencia, Buenos Aires, Ediciones Cooperativas, 2013.
} 
descubrimiento del contenido humano detrás de la objetividad enajenada de las categorías económicas, podría decirse que estos autores realizan lo que hemos caracterizado en otro lado como una lectura feuerbachiana de este aspecto del método desplegado en las obras de madurez de Marx $^{8}$, esto es, como una suerte de lo que Avineri denominaba en su clásico libro la crítica transformativa heredada de Feuerbach ${ }^{9}$. En este sentido, parecería que no hay diferencia metodológica esencial entre el método crítico presente en El Capital y aquél que estructura el primer intento de Marx de realizar la crítica de la economía política que se encuentra en los Manuscritos de 1844. La única diferencia sería que en los textos de madurez Marx no sólo reduce las formas sociales enajenadas a su contenido humano, sino que también se responde (o lo hace de manera más acabada) el por qué dicho contenido asume esa forma fetichizada. Con todo, en cuanto a la modalidad misma de la crítica, el elemento central consiste en dejar al descubierto a la actividad práctica enajenada de los seres humanos como el fundamento social del valor.

Ahora bien, si de lo que se trata es de la transformación radical del mundo, la cuestión que surge entonces es cómo traducir dicho descubrimiento científico del fundamento humano de las categorías económicas en una crítica práctica, esto es, como convertirlo en una praxis consciente emancipadora. $\mathrm{Y}$ es en este punto dónde, en última instancia, se pone de relieve con toda claridad el recurso a un momento de exterioridad respecto de las relaciones sociales capitalistas como fuente de las potencias transformadoras de la acción revolucionaria. A grandes rasgos, estas potencias no residirían en la forma-mercancía misma que rige la práctica humana en el capitalismo, sino en el carácter esencial de un contenido material genérico desprovisto de toda determinación social, el poder constitutivo del trabajo humano, el cual es visto como lógicamente previo a su existencia pervertida como productor de valor (si bien, se declama, es esta última la forma en que se manifiesta y aparece). De este modo, se sigue que para estos enfoques este descubrimiento del contenido humano de las categorías económicas agota el conocimiento necesario para organizar la crítica práctica del capitalismo. Pero examinemos la cosa más de cerca mediante una discusión más detallada de algunas de las contribuciones principales a esta literatura.

Un buen punto de partida es quizás la obra de Hans-Georg Backhaus, quien rastrea el linaje feuerbachiano del método crítico de Marx de manera explícita. De acuerdo a Backhaus, luego de utilizarlo inicialmente en "su crítica a la teoría metafísica del Estado", Marx extendió el campo de aplicación de dicho método a los objetos económicos en tanto formas materiales de la auto-enajenación, la cual es en este sentido conmensurable a sus formas metafísicas y religiosas ${ }^{10}$. Este método, denominado por este autor como "críticogenético", es visto como involucrando dos aspectos fundamentales: el crítico y el antropológico. El primero no consiste tan solo en la descripción y denuncia de las contradicciones entre los postulados teóricos de los diferentes dogmas y la existencia real

\footnotetext{
${ }^{8}$ Guido Starosta, Marx's Capital, Method and Revolutionary Subjectivity, Leiden, Brill, 2015. Ver al respecto en especial el capítulo 1.

${ }^{9}$ Shlomo Avineri, The Social and Political Thought of Karl Marx, Cambridge, Cambridge University Press, 1993.

${ }^{10}$ Hans-Georg Backhaus, "Some Aspects of Marx's Concept of Critique in the Context of his Economic-Philosophical Theory", en Human Dignity: Social Autonomy and the Critique of Capitalism, editado por Werner Bonefeld y Kosmas Psychopedis, Aldershot, Ashgate, 2005, 18-19.
} 
de las instituciones, sino que apunta, en lo fundamental, a la explicación de la génesis inmanente o necesidad de esas contradicciones ${ }^{11}$. A su vez, el momento antropológico del método involucra, tal como ya anticipamos, la reducción ad hominem, esto es, la demostración de la base humana del objeto económico en tanto forma material del autoextrañamiento, quedando de este modo delineado en su totalidad como blanco de la crítica $^{12}$. La crítica de las categorías económicas implica así situarse más allá del punto de vista económico propiamente dicho ${ }^{13}$. Según este autor, Marx recurre a esta "aplicación del método crítico-genético" a la ciencia económica no sólo en sus escritos de juventud (un hecho que consideramos fuera de toda discusión), sino, y aquí de modo más controvertido, en las versiones de madurez de la crítica de la economía política ${ }^{14}$. En efecto, el eje de la crítica permanece inalterado: mientras la ciencia económica "acepta las formas y categorías económicas sin pensamiento, esto es, de manera irreflexiva [...] Marx, en contraposición, busca 'derivar' estas formas y categorías como formas invertidas de las relaciones sociales" $"$.

El "método dialéctico de exposición" es así visto como un desarrollo genético de esas formas enajenadas de objetividad a partir de su base en la práctica humana sensible ${ }^{16}$. Así, se sigue que el método general de la crítica no cambia entre los escritos marxianos tempranos y los tardíos, sólo se altera la terminología ${ }^{17}$. Con todo, cabe la siguiente aclaración de forma de evitar malentendidos. Nuestro planteo no es que estas contribuciones desde la Neue Lektüre consideren que no hay ningún cambio entre la crítica del joven Marx y su versión 'madura'. Pero sí pensamos que no ven ninguna modificación en lo que respecta a la naturaleza y el modo de la crítica: la reductio ad hominem sigue siendo vista como el fundamento de la praxis revolucionaria ${ }^{18}$. Con todo, esta lectura novedosa de la obra marxiana sí desarrolla otros dos elementos metodológicos que son relevantes para la presente discusión.

En primer lugar, estos autores sostienen que, en la crítica marxiana madura, el aspecto genético del método no está basado solo en Feuerbach. En tanto "el mundo invertido del capital" (como valor que se autovaloriza) se parece al segundo mundo suprasensible de Hegel, "el cual en su realidad [...] contiene dentro de sí [...] tanto lo sensible como el primer mundo suprasensible"19, la crítica madura de Marx también echa mano de la Lógica de Hegel para el "desarrollo dialéctico de las categorías"20. En otros términos, el método dialéctico de Hegel le sirvió a Marx para la exposición sintética de la

\footnotetext{
${ }^{11}$ Backhaus, op. cit., 19.

${ }^{12}$ Idem.

${ }^{13}$ Ibid., 23.

${ }^{14}$ Ibid., 21 ss.

15 Ibid., 21.

${ }^{16}$ Ibid., 22.

${ }^{17}$ Ibid., 25.

${ }^{18}$ Helmut Reichelt, "Social Reality as Appearance: Some Notes on Marx's Conception of Reality", en Human Dignity: Social Autonomy and the Critique of Capitalism, editado por Werner Bonefeld y Kosmas Psychopedis Aldershot, Ashgate, 2005, 38.

${ }^{19}$ Ibid., 32.

${ }^{20}$ Ibid., 43.
} 
secuencia necesaria de determinaciones formales entendidas como "formas objetivas del pensamiento" 21 .

En segundo lugar, recurriendo al concepto de sociedad de Adorno en tanto "unidad de sujeto y objeto" 22 , el cual involucra un "proceso continuo de inversión de subjetividad en objetividad y viceversa" 23 , tanto Backhaus como Reichelt plantean que la determinación enajenada de los seres humanos como "personificaciones de categorías económicas" o "máscaras" (Charaktermaske) es un elemento central del método dialéctico de Marx en El Capital. ${ }^{24}$ Considerada en sí misma, esta idea podría ser un punto de partido programático muy prometedor para una investigación crítica de las determinaciones de la subjetividad revolucionaria. Desafortunadamente, no es este el camino por el que avanzan estos autores. Sus desarrollos tienden a ubicarse en un muy alto nivel de abstracción, alrededor de las determinaciones formales más simples del capital. Como remarcan los miembros del colectivo Endnotes, "la clase casi no juega ningún rol en los escritos de Backhaus y Reichelt, quienes tratan la cuestión de la revolución como si estuviera fuera de su especialidad académica" 25 .

Huelga decir que el hecho de que científicos sociales cuyo programa de investigación gira en torno a la noción marxiana de crítica consideren que la cuestión de la subjetividad revolucionaria cae "fuera de su área de especialización" es, cuanto menos, extraño. La verdadera razón de este desinterés parece residir en un nivel más profundo y es en realidad política. Como Endnotes agrega: "La mayoría de los comentarios sobre la Neue Marx-Lektüre entienden que una de sus principales características es el rechazo a la misión histórica del proletariado que Marx le atribuía y, en efecto, en la izquierda alemana ha tendido a prevalecer una sensibilidad de escepticismo hacia la lucha de clases" ${ }^{26}$. De hecho, aunque rara vez se discute la cuestión de modo explícito, hay ciertos pasajes en el trabajo de estos autores que dan la impresión que tenderían a situar la fuente de la subjetividad revolucionaria en un momento de la individualidad humana que trasciende su existencia enajenada como máscara. Por ejemplo: "Marx presenta a los seres humanos mismos solo en tanto se vinculan entre sí como máscaras. En tanto se relacionan mutuamente como individuos, no constituyen un objeto teórico. En tanto actúan como individuos, no están incluidos en la construcción teórica en este sentido específico; anticipan algo que todavía debe ser construido" 27 . Si nuestra lectura es correcta, más que residir fuera de su campo de especialización, para estos investigadores la subjetividad revolucionaria directamente queda fuera de la presentación dialéctica de las categorías económicas. De todas maneras, es posible examinar las implicaciones prácticas de este enfoque mediante el examen del trabajo de Werner Bonefeld quien, no sólo ha divulgado estas ideas fuera de los círculos germanoparlantes, sino que, en calidad de figura central de la corriente del Marxismo

${ }^{21}$ Ibid., 57.

${ }^{22}$ Hans-Georg Backhaus, "Between Philosophy and Science: Marxian Social Economy as Critical Theory", en Open Marxism, Volume 1: Dialectics and History, editado por Werner Bonefeld, Richard Gunn et al., London, Pluto Press, $1992,56$.

${ }^{23}$ Backhaus, op. cit., 60.

${ }^{24}$ Idem; Helmut Reichelt, "From the Frankfurt School to Value-Form Analysis", Thesis Eleven, 4, 1982, $166-9$.

${ }^{25}$ Endontes, 99.

${ }^{26}$ Ibid., 98.

${ }^{27}$ Reichelt, op. cit., 1982, 168. 
abierto, las ha desarrollado en una línea decididamente política, esto es, poniendo la lucha de clases revolucionaria en el eje de su investigación ${ }^{28}$.

\section{Politizando la Neue Marx-Lektüre: Bonefeld y el Marxismo abierto}

Un artículo reciente de Bonefeld sobre Adorno y la praxis social resulta un terreno fértil para discutir la cuestión ${ }^{29}$. El punto de partida de Bonefeld es el reconocimiento de que en el capitalismo "la objetivación del sujeto existe en una forma invertida, en la cual la cosa misma se subjetiva en la persona, y la persona se objetiva en la cosa" ${ }^{30}$. En otras palabras, Bonefeld rescata aquí la idea adorniana que en un principio disparó la Neue MarxLektüre, según la cual, en esta sociedad, los individuos están determinados como "máscaras" o "agentes del valor": su actividad social deviene la actividad de "personificaciones de categorías económicas" "31. En términos ya abiertamente adornianos, Bonefeld refiere a este fenómeno como involucrando una "conceptualidad objetiva" específica, la cual "impera en la realidad (Sache) misma"32. Sin embargo, a diferencia de Backhaus y Reichelt, este autor formula de modo explícito la pregunta acerca de las implicaciones de esta determinación formal de la individualidad humana para la praxis emancipatoria, esto es, para la lucha de clases revolucionaria ${ }^{33}$.

Lo interesante de la respuesta de Bonefeld a esta pregunta es que, al menos en principio, rechaza aquellos intentos de fundar la "resistencia" a la reificación en un "sujeto simplemente postulado, concebido en contraposición a la sociedad", y cuyo fundamento transhistórico estaría constituido por "la humanidad y el espíritu" del obrero (Lukács), "el carácter trascendente interior de la materia" (Bloch), "un instinto materialista" (Negt y Kluge) o el "biopoder" (Hardt y Negri) ${ }^{34}$. En otras palabras, Bonefeld se desvive por evitar recaer en cualquier exterioridad respecto de las formas pervertidas de existencia del individuo social como fundamento del sujeto revolucionario.

Bonefeld elabora estas ideas a través de una discusión filosófica de la concepción de Hegel sobre la relación entre esencia y apariencia. La esencia, argumenta Bonefeld siguiendo a Hegel, tiene que aparecer (no puede elegir no hacerlo). Asimismo, esta apariencia es su (único) modo de existencia. Esto implica que no hay exterioridad a la manifestación efectiva de la esencia, por más pervertida que esta última sea: "su aparecer es al mismo tiempo su desaparición". ${ }^{35}$ En el lenguaje de la teoría social, este argumento filosófico significa que la práctica sensible humana (la esencia) existe como personificación de categorías económicas (la apariencia). Y esto no es una mera ilusión subjetiva, sino que es bien real. Ahora, si bien esto le permite a Bonefeld, al menos en términos formales, no

\footnotetext{
${ }^{28}$ Endontes, op. cit., 98.

${ }^{29}$ Werner Bonefeld, "Negative Dialectics in Miserable Times: Notes on Adorno and Social Praxis", Journal of Classical Sociology, 12(1), 2012, 122-34.

${ }^{30}$ Bonefeld, op. cit., 125.

${ }^{31}$ Ibid., 124.

${ }^{32}$ Ibid., 125-6.

${ }^{33}$ Werner Bonefeld, "History and Human Emancipation: Struggle, Uncertainty and Openness", Critique, 38(1), 2010, 6173.

${ }^{34}$ Bonefeld, op. cit., 2012, 131.

35 Ibid., 138.
} 
terminar postulando un vínculo exterior entre el sujeto humano y la sociedad, surge de todos modos la pregunta de cómo evitar el callejón sin salida político al cual sucumbió, con su pesimismo característico, el propio Adorno. Es decir, surge la pregunta de cómo evitar la conclusión de que "no puede haber tal cosa como praxis emancipatoria dado que el mundo cosificado de la sociedad burguesa sólo daría lugar a una actividad cosificada"36.

Y llegamos aquí al quid de la cuestión. Porque, a nuestro juicio, Bonefeld sólo puede mantenerse fiel al proyecto de la praxis emancipatoria al costo de echarse atrás en sus intenciones de rechazar toda exterioridad entre esencia y apariencia. Así, inmediatamente después de afirmar que la primera desaparece en la segunda, avala el planteo de Adorno en Dialéctica Negativa, donde sostiene que "la contradicción [...] es índice de lo que hay de falso en la identidad, en la adecuación de lo concebido con el concepto", es decir, que "los objetos son más que su concepto" 37 . De acuerdo a Bonefeld, la clave de la crítica está en "la apertura de lo no-conceptual dentro de lo conceptual"38. Este contenido no conceptual, continúa Bonefeld, "subsiste dentro de su concepto pero no puede reducirse a él" 39 . De modo crucial, es este momento de irreductibilidad del contenido que, en tal simpleza e inmediatez, constituye el fundamento de la subjetividad revolucionaria. En otras palabras, esta última es vista por Bonefeld como expresión de la afirmación directa, no mediada, del contenido no conceptual. Y nada cambia por el hecho de que no ve esta afirmación como pura positividad sino como negación de la "condición humana negativa". Pues el punto es que la fuente inmediata de esa negatividad la encuentra en el contenido (informe) mismo: "la subversión es capaz de negar el orden establecido porque este último es un producto humano" $"$. El postulado de inmanencia entre contenido y forma resulta, en última instancia, una declaración formal que es desmentida por el curso subsiguiente de la argumentación. Al final, se termina colando un elemento de exterioridad a la práctica social enajenada como la sustancia residual que constituye la subjetividad revolucionaria. La lucha de clases revolucionaria es vista entonces por Bonefeld como expresión de aquella práctica humana sensible negada por el "capital variable". De hecho, su punto parecería ser que todas las luchas obreras expresan algo más que su determinación social como personificaciones del capital variable, a saber: su "autonomía social humana" y su "libertad". Es por ello que estas luchas siempre encierran la potencialidad de desarrollarse, en y por sí mismas (esto es, no como expresión de alguna determinación social concreta), en luchas comunistas ${ }^{41}$.

Volveremos más abajo sobre los problemas sustantivos de este tipo de enfoque. Por el momento, quisiéramos detenernos en un aspecto metodológico implícito en esta concepción sobre la subjetividad revolucionaria. En particular, examinemos cuáles son las implicaciones de esta perspectiva para el significado de la ciencia como crítica. Como vimos, para Bonefeld la crítica dialéctica se reduce a la desmitificación de las categorías económicas mediante el develamiento de su constitución social como modos de existencia

\footnotetext{
${ }^{36}$ Ibid., 124.

${ }^{37}$ Theodor Adorno, Dialéctica Negativa, Madrid, Taurus, 1992, 13.

${ }^{38}$ Bonefeld, op. cit., 2012, 130.

${ }^{39} \mathrm{Ibid}$., énfasis agregado.

${ }^{40}$ Bonefeld, op. cit., 2010, 66.

${ }^{41}$ Ibid., 68-72.
} 
pervertidos de la actividad humana, es decir, mediante el descubrimiento de la práctica sensible como el contenido negado detrás de esas formas cosificadas de mediación social. Se sigue entonces que el momento "subversivo" del programa metodológico de Marx es, en lo fundamental, analítico: el mismo consiste en el descubrimiento del contenido inmanente a una forma determinada. Tomando inspiración del trabajo de Backhaus que comentamos más arriba, en esta concepción de la ciencia como crítica se trata de arrojar luz sobre la práctica revolucionaria a través de la reductio ad hominem ${ }^{42}$.

El problema de este abordaje es que, tal como hemos argumentado en otro lado, el análisis dialéctico es en sí mismo impotente para ofrecer una explicación de la razón de ser de las formas concretas determinadas de la realidad ${ }^{43}$. Al involucrar un movimiento "hacia atrás" desde una forma concreta a su contenido, el análisis dialéctico puede develar cuáles son las determinaciones más abstractas de lo real cuya realización está presupuesta y portada por la forma concreta bajo examen. Pero lo que el análisis es incapaz de hacer es dar cuenta del "por quê" de dicha forma concreta, esto es, de su necesidad inmanente. En este sentido, el descubrimiento analítico del contenido humano de las relaciones fetichizadas entre cosas realiza un aporte necesario pero modesto y limitado a la comprensión de la subjetividad revolucionaria. De hecho, este descubrimiento es uno de los logros de la crítica del joven Marx a la economía política ya en los Manuscritos de 1844. Esto por cierto le permitió comprender la determinación (humana) más simple o abstracta subyacente al contenido y la forma de la abolición del fetichismo de las relaciones sociales capitalistas. Pero, de hecho, el sentido de la empresa científica subsiguiente en la cual se embarcó Marx consistió en avanzar en la comprensión de las mediaciones ulteriores involucradas en la constitución material y social del sujeto revolucionario, lo cual sólo podía resultar del progreso sintético en su reproducción ideal.

Ahora bien, es evidente que esto presupone que uno considera que en efecto existen tales mediaciones que deben ser desarrolladas sintéticamente de modo de comprender la práctica revolucionaria. Pero esto es lo que el enfoque de Bonefeld rechaza. Como hemos argumentado, a pesar de su crítica a las perspectivas que apelan a un "sujeto postulado contrapuesto exteriormente a la sociedad", su propio abordaje termina encontrando el fundamento inmanente a la subjetividad revolucionaria en algo simple e inmediato: la abstracta materialidad de la "práctica humana sensible" que "vive en y a través de las relaciones entre cosas". En este punto, la limitación que hace Bonefeld del momento subversivo de la crítica dialéctica al proceso analítico es del todo coherente, al menos en sus propios términos. Pues, en el fondo, desde su perspectiva de hecho no hay determinaciones sociales en juego en la constitución de la subjetividad revolucionaria. Lisa y llanamente, no hay nada que explicar. Dicho en otros términos, la abolición revolucionaria del capital no encierra ninguna necesidad inmanente sea ésta material, social

\footnotetext{
42 Werner Bonefeld, "Review of Hans-Georg Backhaus's 'Dialektik der Wertform: Untersuchungen zur marxschen Ökonomiekritik", Capital and Class, 22(3), 1998, 158-61; Werner Bonefeld, "Kapital and Its Subtitle: A Note on the Meaning of Critique", Capital and Class, 25(3), 2001, 53-63.

${ }^{43}$ Guido Starosta, "The Commodity-Form and the Dialectical Method", Science \& Society, 72(3), 2008, 295-318; Gastón Caligaris y Guido Starosta, "La crítica marxiana de la dialéctica hegeliana", Praxis Filosófica, 41, julio-diciembre, 2015, 81-112.
} 
o histórica ${ }^{44}$. Su única necesidad es moral, la realización práctica del "imperativo categórico comunista de la emancipación humana" ${ }^{45}$. En suma, la emergencia de la subjetividad revolucionaria es para Bonefeld el resultado de una acción política abstractamente libre y socialmente autónoma, entendida como el opuesto absoluto del automatismo enajenado de la forma-capital (si bien se trata de una acción que sólo puede surgir como "negatividad", esto es, en las luchas "en y contra" la opresión capitalista): "la libertad deviene concreta en las formas cambiantes de la represión como resistencia a la represión"46.

Se sigue de esto que lo único que requiere explicación es la constitución social de las formas fetichizadas de objetividad en las cuales existe la práctica humana en el capitalismo. En este sentido, y en aras de hacer una lectura justa del trabajo de Bonefeld, hay que resaltar que él reconoce que la potencia crítica del método dialéctico involucra no sólo análisis sino también la reproducción sintética o "genética". Sin embargo, Bonefeld considera a la reproducción sintética como el único método materialista y científico para el desarrollo genético de las formas sociales pervertidas, es decir, para la comprensión de la constitución social de las formas de objetividad fetichizadas a partir de las relaciones humanas. Pero en cuanto a las formas de subjetividad, sólo son contempladas como parte del desarrollo genético de formas en tanto los individuos "actúan racionalmente como ejecutores de leyes sobre las cuales no tienen ningún control" 47 , lo que para este enfoque constituye el único aspecto bajo el cual los seres humanos actúan como personificaciones de categorías económicas. Pero en lo que hace a las formas antagónicas radicales de subjetividad y acción, ellas parecen quedar fuera del alcance del despliegue sistemático de las categorías económicas (excepto, por supuesto, como instancias de negación absoluta del automatismo de las mismas, i.e. en tanto luchas contra la autonomización de esas formas de objetividad). Por ello puede Bonefeld afirmar: “ ¿Tiene sentido decir que los obreros personifican al capital variable? El capital variable no hace huelga. Los obreros lo hacen" ${ }^{\text {. }}$. Y para Bonefeld no (¿solamente?) lo hacen en su determinación específicamente social como propietarios de fuerza de trabajo en su intento de asegurar la reproducción de la única mercancía que tienen para vender. Fundamentalmente, según Bonefeld, lo hacen también como expresión inmediata de su "dignidad humana", en tanto "la autonomía social no es una especie de futuro distante", sino que está en juego en cada lucha diaria de los obreros contra "la reducción capitalista de las finalidades humanas a un bien económico y al dinero en efectivo" 49 .

\footnotetext{
44 Bonefeld, op. cit., 2010, 63-4. Al dar por buena a la noción ortodoxa de determinación mecánica (y, por ello, extrínseca) de la subjetividad como la única posible, Bonefeld ve en la idea de necesidad histórica una actitud pasiva y complaciente respecto de las leyes de movimiento enajenadas del capital. De allí que concluya que la idea de que la subjetividad revolucionaria encierra determinaciones nunca puede ser el punto de partida de la organización consciente de la abolición de la existencia enajenada de la vida humana. Por supuesto, que la determinación de la subjetividad revolucionaria sea dialéctica y, por ende, inmanente, no es una opción que Bonefeld siquiera considere.

${ }^{45}$ Bonefeld, op. cit., 2010, 66.

${ }^{46}$ Ibid., 71.

${ }^{47}$ Bonefeld, op. cit., 2012, 128.

${ }^{48}$ Bonefeld, op. cit., 2010, 68.

${ }^{49}$ Bonefeld, op. cit., 2010, 72. En rigor, los obreros no hacen huelga en tanto "capital variable" sino en su determinación como propietarios privados de la mercancía fuerza de trabajo. Sea como fuere, el punto es que hacen huelga en modo
} 
En suma, para la versión de Bonefeld del Marxismo abierto, el movimiento sintético de la exposición dialéctica concierne solo a la constitución social de las categorías económicas y al proceso de reproducción continua de la premisa de su existencia en cada transición del desarrollo conceptual. Bonefeld sitúa dicha premisa en la "lógica de separación" del trabajo respecto de sus condiciones objetivas, es decir, en la subsunción formal del trabajo en el capital ${ }^{50}$. Pero la secuencia sistemática no involucra ningún progreso en el conocimiento de las determinaciones inmanentes de la subjetividad revolucionaria. En este sentido, es sintomático el significado que Bonefeld le atribuye al punto culminante de la exposición sistemática de Marx en el tomo I de El capital, el cual, a su modo de ver, debería estar confinado al concepto de acumulación originaria ${ }^{51}$. La sección sobre la "Tendencia histórica de la acumulación capitalista" sólo importa en tanto "continúa el proceso de expropiación en sus propios términos, como centralización del capital" 52 . Pero en lo que respecta a la "expropiación revolucionaria de los expropiadores y el hacer saltar la corteza capitalista" que Marx presenta como el resultado necesario de la socialización enajenada del trabajo privado, Bonefeld considera que debe dejarse de lado como mera "observación desesperadamente triunfalista" ${ }^{53}$. Y esto no debería sorprender. Como hemos mostrado, de acuerdo a su enfoque la subjetividad revolucionaria está autofundada en una abstracta negatividad, la cual se expresa, si bien de forma "contradictoria", en toda manifestación de la resistencia a la opresión (volveremos más abajo sobre el sentido de las comillas). A primera vista, esta concepción parece así exaltar y "empoderar" la acción política de la clase obrera, en contraposición al "fatalismo" y "quietismo" que se seguiría de las perspectivas ortodoxas que plantean la superación del capital en términos de la imposibilidad "mecánica" de su reproducción ampliada, al tiempo que se evitaría caer en el inmediatismo y subjetivismo ingenuo de, por ejemplo, el llamado Marxismo autonomista ${ }^{54}$. Sin embargo, a nuestro juicio, esta perspectiva es también profundamente problemática.

\section{Los Límites del Marxismo abierto}

En términos sustantivos, lo primero que puede señalarse respecto al Marxismo abierto es que, a pesar de su intento por llevar a cabo una crítica radical de las relaciones

\footnotetext{
completamente acorde a su ser social enajenado como "ejecutores de leyes económicas que no pueden controlar" y no en desafío a las mismas.

50 Werner Bonefeld, "Primitive Accumulation and Capitalist Accumulation: Notes on Social Constitution and Expropriation", Science and Society, 75(3), 2011, 395.

51 También es sintomático que en su por lo demás rigurosa reconstrucción estilizada de la secuencia sistemática de la exposición de Marx en el tomo 1 de El capital, las formas concretas de la producción de plusvalía relativa brillan por su ausencia. Ver Bonefeld, op. cit., 2011, 392-5. Como señalaremos más adelante, es justamente en esos capítulos sobre la subsunción real del trabajo en el capital donde Marx despliega ( $\sin$ bien de modo incompleto) las determinaciones de la subjetividad revolucionaria.

52 Bonefeld, op. cit., 2011, 394.

${ }^{53}$ Ibid., 2011, 395.

${ }^{54}$ Ver, por ejemplo, Harry Cleaver "The Inversion of Class Perspective in Marxian Theory: From Valorisation to SelfValorisation", en Open Marxism, Volume II: Theory and Practice, editado por Werner Bonefeld et al., London, Pluto Press, 1992, 128ss; Massimo De Angelis, The Beginning of History: Value Struggles and Global Capital, London, Pluto Press, 2007, 225ss.
} 
sociales capitalistas, su enfoque termina involucrando la naturalización de la forma de la libertad personal del productor privado e independiente y, en consecuencia, la impotencia práctica para abolir el fetichismo de la mercancía y del capital. Examinemos la cuestión más de cerca.

En efecto, tal como ha puesto de relieve Iñigo Carrera ${ }^{55}$ en lo que a nuestro juicio constituye uno de sus aportes más fundamentales a la crítica de la economía política, en el modo de producción capitalista la conciencia libre no es ni el abstracto opuesto ni el contenido auto-negado de la conciencia enajenada en la mercancía como relación social general (y, a fortiori, en el capital). Al contrario, en la sociedad capitalista la conciencia libre de toda sujeción personal no es más que la forma en que la conciencia enajenada del productor de mercancías se afirma en la forma de su propia negación ${ }^{56}$. Es decir, la otra cara de la moneda por la cual el ser humano confronta sus potencias sociales inmanentes como un atributo objetivo exterior a su individualidad portado por el producto del trabajo social (esto es, el valor), es su autoconcepción como el portador de una subjetividad abstractamente libre por naturaleza, cuyo contenido esencial, por ende, es concebido como una pura "autodeterminación" de los individuos ${ }^{57}$. Por ello es que es viéndose y, en consecuencia, actuando, como un sujeto abstractamente libre, que el ser humano afirma y reproduce su propia práctica productiva enajenada, esto es, su plena determinación social como personificación de las formas objetivadas de su relación social general (mercancía, dinero, capital, estado, etc.). Como señala el propio Marx en los Grundrisse, la forma subjetiva de la libertad no es otra cosa que la expresión de que el "individuo solo existe en cuanto productor de valor de cambio" "58.

De modo que, así como la forma económica, el intercambio, pone en todos los sentidos la igualdad de los sujetos, el contenido o sustancia -tanto individual como colectivo- pone la libertad. No sólo se trata, pues, de que la libertad y la igualdad son respetadas, en el intercambio basado en valores de cambio, sino que el intercambio de valores de cambio es la base productiva, real, de toda igualdad y libertad. Estas, como ideas puras, son meras expresiones idealizadas de aquél al desarrollarse en relaciones jurídicas, políticas y sociales,

\footnotetext{
55 Iñigo Carrera, op. cit., 2007.

${ }^{56}$ Para un tratamiento en profundidad de la cuestión, ver el capítulo 3 de Iñigo Carrera, op. cit., 2007.

${ }^{57}$ Nótese que desde un punto de vista materialista, esto es, desde la perspectiva de la organización y el desarrollo de la subjetividad productiva, la libertad no consiste en la ausencia de toda determinación social (esto es, de toda necesidad) en la afirmación de la individualidad humana (consistiendo entonces la enajenación en la imposición de dispositivos sociales de coacción objetiva exterior que constreñirían dicha subjetividad abstractamente libre), sino en el control autoconsciente pleno, tanto del carácter individual como del social inmanente de la acción humana, por parte del propio sujeto que la realiza. En otras palabras, así considerado, el contenido de la libertad está dado por el control consciente de la participación individual en el proceso inherentemente social de metabolismo material humano. En su determinación más simple, y vista desde un punto de vista materialista, la libertad personal del productor privado e independiente consiste de este modo en el control pleno del carácter individual de la acción productiva humana, pero a expensas de todo control sobre su carácter social general inmanente. Ver Iñigo Carrera, op. cit., 2007, 51ss. En este sentido, la superación de la enajenación capitalista involucra la transformación progresiva de la forma misma de la libertad, cuyo contenido o sustancia material sólo puede consistir, preservando el control consciente individual sobre el trabajo humano, en avanzar también en el conocimiento consciente pleno de las determinaciones sociales inmanentes del trabajo por parte de cada uno de los sujetos de dicha acción productiva y, en consecuencia, en el reconocimiento racional de la propia necesidad de regular sus respectivos procesos individuales de vida como una potencia directamente colectiva.

${ }^{58}$ Karl Marx, Elementos Fundamentales para la Crítica de la Economía Política (Grundrisse), México, D.F., Siglo XXI, 1989, 186, énfasis agregado.
} 
éstas son solamente aquella base elevada a otra potencia. Por lo demás, ello ha sido confirmado históricamente. La igualdad y la libertad en este sentido constituyen precisamente lo contrario de la libertad e igualdad en la Antigüedad, que no tenían como base el valor de cambio desarrollado; antes bien, fueron arruinadas por el desarrollo de aquél. La igualdad y la libertad presuponen relaciones de producción que aún no estaban realizadas en el mundo antiguo; tampoco en la Edad Media ${ }^{59}$.

Ahora bien, hemos visto que a pesar de los denodados esfuerzos del Marxismo abierto por eliminar toda exterioridad entre la práctica humana y sus formas sociales de existencia enajenada, a la hora de explicar las potencias transformadoras radicales de la clase obrera, estos autores terminan reintroduciendo por la puerta trasera un aspecto de la subjetividad que se pone en movimiento y actúa no en tanto personificación de su ser social (cosificado como está en la forma de capital), sino como expresión inmediata del "poder constitutivo" genérico (o la "dignidad") del trabajo humano. En este sentido, puede concluirse sin lugar a dudas que la acción revolucionaria aparece así representada como abstractamente libre y el contenido de dicha libertad como autodeterminación de la clase obrera (pues no se considera que exprese ninguna necesidad inmanente de su relación social general enajenada, sino que es vista como una acción que no tiene más necesidad que la que brota de la propia voluntad transformadora del proletariado). Es entonces la afirmación inmediata de esta abstracta libertad humana lo que constituye la fuente de la potencia para la superación revolucionaria de la existencia social enajenada en el capital.

Y esto nos lleva a la segunda debilidad de este enfoque, la cual tiene un cariz más metodológico. En concreto, consideramos que, a pesar de las referencias a las "relaciones internas o dialécticas", el mismo encierra la representación exterior del vínculo inmanente entre el contenido y la forma concreta de la subjetividad revolucionaria, en términos de una pseudo-dialéctica consistente en la "unidad de opuestos antagónicos". Porque es notorio cómo la contradicción, que al comienzo del razonamiento se postula de modo correcto, al menos en términos formales, como la forma de existencia autonegada de un contenido determinado (esto es, el movimiento de afirmarse a través de la propia negación), se transforma subrepticiamente, en el curso mismo de la argumentación, en la "interpenetración" de dos afirmaciones inmediatas diferentes unidas de manera extrínseca en un proceso de "lucha de opuestos" $"$. Si bien esto está sin dudas presente en varios de los escritos de Bonefeld ${ }^{61}$, aparece de manera mucho más nítida y expresiva en la obra de Richard Gunn, quien tal vez sea el autor que más haya aportado a las reflexiones metodológicas del Marxismo abierto. De modo interesante y relevante para este artículo, en lo que es tal vez un artículo fundacional y clave desde esta perspectiva, la cuestión está abordada en términos del vínculo contradictorio entre libertad y enajenación en el capitalismo $^{62}$.

\footnotetext{
${ }^{59}$ Marx, op. cit., 183.

${ }^{60}$ Iñigo Carrera, op. cit., 2013, capítulo 1; Starosta, op. cit., 2015, cap. 3.

${ }^{61}$ Werner Bonefeld, The Recomposition of the British State During the 1980s, Aldershot, Dartmouth, 1993, 26-8.

${ }^{62}$ Richard Gunn, "Against Historical Materialism: Marxism as a First-Order Discourse", en Open Marxism, Volume II: Theory and Practice, editado por Werner Bonefeld, Richard Gunn et al., London, Pluto Press, 1992, 1-45.
} 
El punto de partida de Gunn es, ya de por sí, problemático, en tanto postula de manera manifiesta a la "libertad qua autodeterminación" como un rasgo general y, por ende, transhistórico, del "ser genérico humano", siendo esto lo que lo diferencia de las formas simplemente naturales del mundo material ${ }^{63}$. Pero lo que nos interesa resaltar aquí es cómo se enfrenta al problema de la enajenación y su superación revolucionaria en el capitalismo, lo cual es presentado por Gunn como encerrando la aparente paradoja: "si nos movemos libremente entonces no éramos no-libres para empezar, pero si no nos movemos libremente, entonces la libertad no puede ser nunca el resultado (al menos no en el sentido de autodeterminación)"64. El "truco", continúa Gunn, consiste ver a la "carencia de libertad como el modo de existencia de la libertad" 65 . En este sentido, sostiene que "en realidad no hay tal cosa como la ausencia de libertad, sino solo la 'libertad no libre', lo cual equivale a la libertad subsistiendo enajenadamente, esto es, en el modo de ser negada" ${ }^{66}$. En resumidas cuentas, dejando por el momento de lado la forma invertida en que representa el vínculo entre "libertad qua autodeterminación" y enajenación en el capitalismo, es claro que hasta aquí su argumento gira en torno al afirmarse mediante la propia negación de un contenido en su forma de realizarse, esto es, al movimiento de la contradicción.

¿Cómo es, según Gunn, que esta contradicción entre el contenido de libertad esencial de la subjetividad humana y su modo de existencia enajenado se desarrolla en la forma de una acción revolucionaria que pone fin a la enajenación? Para ver como aborda Gunn la cuestión, cambiemos el foco de nuestra atención a un artículo más reciente en coautoría con Adrian Wilding, donde, en el contexto de una evaluación crítica "amigable" y empática del libro de John Holloway Crack Capitalism ${ }^{67}$, revisita y elabora ulteriormente su anterior argumento ${ }^{68}$. Los términos del problema son similares, planteados ahora en la antinomia aparente que rastrean en el libro de Holloway entre lo que denominan la visión "atractiva" de la revolución, según la cual la libertad existe ya en forma prístina y sin distorsiones en una situación pre-revolucionaria (haciendo la tarea revolucionaria posible pero demasiado sencilla y voluntarista), y la visión "no atractiva", la cual asume que la libertad está completamente ausente en una situación pre-revolucionaria (lo cual suena más "realista" pero, de acuerdo a estos autores, hace imposible que de la misma resulte la libertad) ${ }^{69}$. La solución para esta antinomia pasa, en sintonía con el argumento de Gunn reseñado más arriba, por reconocer tanto que la revolución es en efecto un acto que pone fin a la servidumbre voluntaria y, en tal condición, "es una expresión y articulación de una acción que ya es libre", ${ }^{70}$ como que en una situación pre-revolucionaria, tal libertad existe, pero "en una forma distorsionada" o "autocontradictoria y enajenada"71. De este modo, la

\footnotetext{
${ }^{63}$ Gunn, op. cit., 28.

${ }^{64}$ Ibid., 29.

${ }^{65}$ Idem.

${ }^{66} \mathrm{Idem}$.

${ }^{67}$ John Holloway, Crack Capitalism, London, Pluto Press, 2010.

${ }^{68}$ Richard Gunn y Adrian Wilding, 'Holloway, La Boétie, Hegel', Journal of Classical Sociology, 12(2), 2012, 173-90; ver también Richard Gunn y Adrian Wilding, 'Recognition Contradicted', South Atlantic Quarterly, 113(2), 339-52, 2014.

${ }^{69}$ Gunn y Wilding, op. cit., 2012, 178-80.

${ }^{70}$ Ibid., 178.

${ }^{71}$ Ibid., 181-2.
} 
cuestión es vista como un pasaje de una situación donde la libertad ya está presente, pero en forma enajenada (situación pre-revolucionaria), a una donde la libertad existe en una forma no enajenada (la revolución). En otros términos, la mediación (y de allí, la enajenación) solo aplica para Gunn y Wilding en los momentos de la subjetividad que reproducen al capital. Pero no juega ningún papel directo en el "polo revolucionario" de lo que Bonefeld denomina "continuo dialéctico" entre integración y trascendencia ${ }^{72}$, el cual es visto como la afirmación inmediata (es decir, no mediada) de una subjetividad naturalmente libre y autodeterminada, que se abre camino a través de su "corteza" capitalista enajenada.

Esto queda manifiesto, por partida doble, en la forma en que conceptualizan a la "autodeterminación no contradictoria". En primer lugar, cuando argumentan que en una situación que de modo general es no revolucionaria, tal autodeterminación no contradictoria ya aparece dentro una sociedad enajenada, si bien en un modo "proléptico o prefigurado", en y a través de "islas de reconocimiento mutuo" en las "grietas y fisuras" de un mundo social contradictorio. De un plumazo, el movimiento de afirmarse a través de la propia negación pasa ahora a estar representado, tal como señalábamos más arriba, en la forma de una unidad exterior entre dos afirmaciones inmediatas opuestas, pero "entrelazadas": un polo enajenado para la mayoría de la existencia social, y uno libre en las "islas de reconocimiento mutuo". En segundo lugar, es manifiesto también en la forma en que construyen su concepto de libertad sobre la base del concepto de reconocimiento de Hegel desplegado en la llamada "dialéctica amo-esclavo" en el capítulo IV de la Fenomenología del Espíritu, y desarrollado y expuesto de un modo más histórico en el capítulo VI, donde se discuten los "patrones de reconocimiento" que culminan en la revolución francesa. Es decir, Gunn y Wilding construyen el fundamento de la revolución comunista basados en un marco conceptual cuyo contenido efectivo no es sino el surgimiento y desarrollo concreto de la libertad autodeterminada moderna-capitalista del propietario de mercancías a partir de la disolución de las relaciones de dependencia personal, lo cual Hegel presenta en forma ideológica e invertida como si se tratara de un abstracto movimiento de la conciencia individual desprovista de determinaciones sociales ${ }^{73}$.

Como consecuencia de todo esto, la crítica "amigable" que Gunn y Wilding hacen del modo en que Holloway termina en ocasiones apelando a una libertad "prístina" y "no distorsionada", queda reducida a notar que "tal inmediatez que cae fuera del reino de la alienación" no puede tomarse "como punto de partida" en la búsqueda de la génesis de la subjetividad revolucionaria dentro de una situación no revolucionaria ${ }^{74}$. Sin embargo, sí constituye la clave (y de allí, el contenido) de su surgimiento intersticial y eventual proliferación. A fin de cuentas, y a pesar de sus mejores esfuerzos por tomar distancia del voluntarismo ingenuo de los autonomistas, lo que diferencia al planteo del Marxismo abierto se reduce a una actitud subjetiva más cauta y sobria a la hora de evaluar las

\footnotetext{
${ }^{72}$ Bonefeld, op. cit., 1992, 102.

${ }^{73}$ No es sorprendente en este contexto que Gunn y Wilding también retomen a La Boétie y su Discurso sobre la Servidumbre Voluntaria, un autor de mediados del siglo XVI que a todas luces lo que está enfrentándose es la cuestión de la disolución de las relaciones directas de autoridad entre seres humanos, en el contexto del avance (ya a esa altura irrefrenable) de las relaciones mercantiles como forma general de mediación social. No por nada la servidumbre de la que trata el discurso y a la que quiere poner fin es la de la voluntad que está sujeta al poder personal del tirano.

${ }^{74}$ Gunn y Wilding, op. cit., 2012, 184.
} 
potencialidades transformadoras de las luchas de la clase obrera realmente existentes. En efecto, en contraposición "a la poesía eufórica y triunfalista que prevalece en varios de los enfoques influenciados por el Marxismo autonomista", la perspectiva Marxista abierta de Gunn y Wilding "da cabida al respeto al principio de realidad (en el sentido de Freud)",75, una "advertencia" acerca de las dificultades y complejidad involucradas en la revolución. Pero, nuevamente, el fundamento de la acción revolucionaria sigue siendo el mismo: una subjetividad abstractamente libre y autodeterminada.

Ahora bien, ¿de dónde brota esta noción de una subjetividad libre qua autodeterminada por naturaleza que, de acuerdo a los enfoques aquí examinados, constituye el contenido de la acción revolucionaria? Por cierto, no de la imaginación de estos autores. Cuando se mira la cosa más de cerca, puede reconocerse que dicha subjetividad abstractamente libre no es otra cosa que la forma concreta de la conciencia enajenada del productor de mercancías, abstraída de su contenido, para luego ser transformada en su abstracto opuesto "lógico-dialéctico". Así, desde tal exterioridad respecto de su contenido, dicha libertad respecto de toda subordinación personal, en tanto forma en que se afirma la subordinación del productor privado e independiente a las potencias sociales enajenadas como el valor del producto de su trabajo social, es luego presentada como la fuente de la negación revolucionaria de la consciencia enajenada en el capital. La misma aparece entonces representada como la emancipación respecto de la coacción, vista irremediablemente así como exterior, que ejerce las formas cosificadas de mediación social capitalista sobre la autodeterminación de la subjetividad abstractamente libre del ser humano. En otros términos, esos enfoques plantean eliminar la mercancía, el dinero, el capital, el Estado, etc., justamente sobre la base de la afirmación inmediata de la forma subjetiva de existencia más general de la práctica humana enajenada en el capital y que constituye el complemento necesario de sus formas objetivadas, a saber: la libertad personal de las personificaciones de mercancías ${ }^{76}$. Lo cual constituye, a todas luces, un oxímoron. En suma, la conexión entre la ciencia como crítica y la abolición del fetichismo de las relaciones sociales capitalistas requiere de una formulación distinta. En la sección siguiente, proponemos y elaboramos dicha alternativa.

\footnotetext{
75 Ibid., 182.

${ }^{76}$ Por cierto, algunos autores desarrollan y someten a crítica la noción de "individualidad burguesa". Pero la misma es reducida al individualismo y egoísmo, esto es, a la afirmación atomizada de la libertad personal. De allí que la afirmación de dicha subjetividad abstractamente libre mediante una acción colectiva organizada de modo solidario, tal como sucede en la lucha de clases, les parezca como el opuesto absoluto de la subjetividad enajenada (o al menos como encerrando la potencialidad inmediata de autotransformarse en tal negación absoluta de la "individualidad burguesa"). Al respecto ver, por ejemplo, la derivación que hace Shortall de una "contra-dialéctica de la lucha de clases" - esto es, de "la subjetividad de clase potencial de clase obrera"-, la cual "viene a delimitar el funcionamiento de la dialéctica del capital" y que encuentra fundamento en la premisa del obrero "tanto como sujeto libre y como no-capital", Felton Shortall, The Incomplete Marx, Aldershot, Avebury, 1994, 128-9. En contraste, hemos mostrado en otro lado que la afirmación colectiva solidaria de dicha subjetividad abstractamente libre no es más que otro modo de existencia más desarrollado del mismo contenido enajenado que en su forma más simple atomizada individual. Ver Starosta, op. cit., 2015, capítulo 7.
} 


\section{El fetichismo de la mercancía y la ciencia como crítica práctica}

Como adelantamos en la introducción, encontramos las herramientas para dicho enfoque alternativo en los aportes sustantivos y metodológicos de Iñigo Carrera a la crítica de la economía política. De acuerdo a esta perspectiva, la cuestión de la ciencia como crítica debe encararse de un modo radicalmente diferente. Se trata de un desarrollo del método dialéctico que, en tanto se autoreconoce en su condición material intrínseca como momento organizacional inmanente a la acción humana, da a la ciencia la forma específica de crítica práctica. En este sentido, el verdadero punto de partida y objeto inmediato de la crítica dialéctica de la economía política es la pregunta por la organización consciente de la acción transformadora radical que apunta a revolucionar las formas de la vida social. De lo que se trata no es de la lucha de clases reducida a mero objeto de un proceso de conocimiento puramente teórico ${ }^{77} \mathrm{y}$, como tal, irreduciblemente exterior a la práctica, sino de la investigación científica acerca de la organización consciente de la propia acción transformadora en su singularidad, si bien reconocida como momento orgánico individual de tal acción colectiva revolucionaria. Puesto en otros términos, lo que está en juego es el conocimiento objetivo pleno de las determinaciones sociales, la necesidad inmanente, de la propia acción individual ${ }^{78}$. Sólo sobre esta base es posible alcanzar la transformación voluntaria del mundo de un modo revolucionario.

Veíamos también más arriba que, desde el punto de vista del método científicocrítico necesario para descubrir las determinaciones del sujeto revolucionario de modo inmanente, tanto para la Neue Marx-Lektüre como para el Marxismo abierto el momento desfetichizador de la crítica de la economía política se limita al movimiento analítico de la reductio ad hominem, por medio del cual se rastrea el origen humano de las formas objetivadas de mediación social capitalista. Nótese en este sentido que, al menos en lo que hace al conocimiento del fundamento de la subjetividad revolucionaria, el momento crítico propiamente dicho de la investigación dialéctica se agotaría en la exposición de la expresión más simple y general de la enajenación capitalista, esto es, en el "fetichismo de la mercancía". En contraste, nuestra perspectiva alternativa de la investigación dialéctica lleva a conclusiones diferentes respecto de la conexión entre la praxis revolucionaria y estas formas fetichizadas de la relación social general que dan unidad a la vida social.

En este proceso de conocimiento adquirimos la conciencia del contenido humano subyacente a las potencias sociales objetivas portadas, en su forma más simple, por la mercancía. Sin embargo, lo que se sigue de este descubrimiento no es que desarrollamos en forma inmediata la potencia transformadora para negar la forma mercantil de nuestra relación social general. Más bien, lo único que puede concluirse en este punto es que cualquiera sea el poder que podamos llegar a tener para transformar radicalmente el mundo, el mismo no puede ser sino una forma concreta de la propia mercancía. Pero lejos de

\footnotetext{
${ }^{77}$ Gunn, op. cit., 1992; Werner Bonefeld, "Social Constitution and the Form of the Capitalist State", en Open Marxism, Volume I: Dialectics and History, edited by Werner Bonefeld, Richard Gunn et al., London, Pluto Press, 1992, 93-132; Werner Bonefeld "Capital as Subject and the Existence of Labour", en Open Marxism, Volume 3: Emancipating Marx, editado por Werner Bonefeld, Richard Gunn et al., London, Pluto Press, 1995, 182-212.

78 Juan Iñigo Carrera, El Conocimiento Dialéctico, Buenos Aires, Centro para la Investigación como Crítica Práctica, $1992,1$.
} 
develar la existencia de tal potencia transformadora, las determinaciones más abstractas del ser social en el modo de producción capitalista contenidas en la mercancía no muestran más potencialidad que la reproducción de dicha forma social enajenada. Y hasta tal punto es así que la asociación libre de los individuos o comunismo (la negación determinada del capitalismo) aparece en el capítulo 1 de El capital (dicho sea de paso, en la sección 4 sobre el carácter fetichista de la mercancía), como un abstracto opuesto del trabajo productor de valor, esto es, como el producto extrínseco de la imaginación del sujeto embarcado en el proceso de conocimiento. Así, Marx abre el pasaje en el que se refiere a dicha asociación libre diciendo: "Imaginémonos finalmente, para variar, una asociación de hombres libres que trabajen con medios de producción colectivos y empleen, conscientemente, sus muchas fuerzas de trabajo individuales como una fuerza de trabajo social"79.

El corolario de esto es, entonces, que el momento crítico de la ciencia revolucionaria no se reduce al descubrimiento del poder constitutivo de una genérica práctica humana como el contenido negado en las formas enajenadas capitalistas, la cual por sí misma y en esa simpleza, constituiría el fundamento inmediato de la transformación radical del mundo. Al contrario, el resultado de la exposición crítica del fetichismo de la mercancía es la autoconciencia de que la reproducción de la vida humana en la unidad general de todos sus momentos toma una forma enajenada en el capitalismo. Y esto, por supuesto, también incluye a nuestra voluntad transformadora. Lo que resulta de este momento de la investigación dialéctica es, así, el desarrollo de la consciencia respecto de la propia enajenación. La mercancía es la forma (objetivada) que toma nuestro ser social general, esto es, la organización de la materialidad de nuestro proceso de vida humano. Por ello, a no ser que se postule que hay algo más en juego que las relaciones sociales que median el establecimiento de la unidad material del proceso de metabolismo social, no hay exterioridad posible a dicha forma enajenada del ser social. Esto no sólo quiere decir que el fetichismo no es una mera ilusión, sino que es total, lo cual, a su vez, significa que las potencias sociales de nuestra acción transformadora están, en efecto, portadas de forma invertida por el producto del trabajo y no podemos sino personificarlas.

Esto trae a colación la cuestión discutida anteriormente acerca del vínculo entre libertad y enajenación. En particular, esto significa que al desarrollar la consciencia del origen humano de la forma-valor, no dejamos de estar determinados como sus personificaciones para pasar a afirmar nuestra acción como abstractamente libre y autodeterminada. Como señala Iñigo Carrera, lo que este descubrimiento cambia es que nuestra determinación como personificación de la mercancía deja de operar a nuestras espaladas $^{80}$. De este modo, efectivamente avanzamos en la afirmación de nuestra libertad. Pero no lo hacemos por darnos cuenta de que en realidad somos seres libres por naturaleza y que entonces podemos elegir a nuestro antojo "dejar de hacer el capitalismo" si nos esforzamos lo suficiente, es decir, si le damos la espalada a nuestro ser social ${ }^{81}$. Al contrario, mediante la investigación científico-crítica de la forma-valor afirmamos nuestra

\footnotetext{
${ }^{79}$ Karl Marx, El Capital. Crítica de la Economía Política, Tomo I, México, D.F., Siglo XXI, 1999, 96.

${ }^{80}$ Iñigo Carrera, op. cit., 2007, 204.

${ }^{81}$ Ver, por ejemplo, especialmente Holloway, op. cit., 2010, 95, 254; ver también John Holloway, Change the World without Taking Power: The Meaning of Revolution Today, London, Pluto Press, 2002.
} 
libertad porque conocemos de modo plenamente consciente nuestra propia determinación como sujetos sociales enajenados. Armados con dicho conocimiento objetivo acerca del carácter enajenado de nuestra subjetividad, podemos actuar en forma consciente sobre esas determinaciones enajenadas de forma de transformarlas en dirección de su superación revolucionaria. Por supuesto, esto sólo sería posible si esas determinaciones de hecho portaran la potencia objetiva para su autoabolición, lo cual, con las determinaciones contenidas en la mercancía en tanto forma más simple de la relación social general de producción, no es el caso. Huelga decir que de esto no se desprende sin más que el fetichismo de la mercancía no puede ser abolido. Sólo indica la necesidad de seguir progresando en la investigación dialéctica hacia determinaciones sociales más concretas de dicha abolición revolucionaria del carácter fetichista del ser social.

Quizás una buena manera de aclarar este argumento es examinar una observación metodológica exterior que Marx introduce al discutir la función del dinero como medio de pago en la Contribución a la crítica de la economía política de 1859. Vale la pena citar extensamente este pasaje profundamente rico:

Sin embargo, el proceso de la metamorfosis de las mercancías, que engendra las diversas determinaciones formales del dinero, metamorfosea asimismo a los poseedores de mercancías o altera las características sociales dentro de las cuales se manifiestan recíprocamente. En el proceso de metamorfosis de la mercancía, el custodio de ésta cambia de piel tantas veces como mude la mercancía o como el dinero cristalice en formas nuevas. Así, originariamente los poseedores de mercancías sólo se hallaban enfrentados entre sí como poseedores de mercancías, luego se convirtieron uno en vendedor y el otro en comprador, después cada cual, alternadamente, en comprador y vendedor, luego en atesoradores, y por último en gentes ricas. De este modo, los poseedores de mercancías no salen del proceso de la circulación del mismo modo en que entraron en él. De hecho, las diversas determinaciones formales que adquiere el dinero en el proceso de la circulación, son sólo la metamorfosis cristalizada de las propias mercancías, la cual, a su vez, es sólo la expresión objetiva de las mutables relaciones sociales dentro de las cuales los poseedores de mercancías llevan a cabo su proceso metabólico. Dentro del proceso de la circulación surgen nuevas relaciones de tráfico y, en cuanto vehículos de estas relaciones modificadas, los poseedores de mercancías adquieren nuevas características económicas ${ }^{82}$.

Este texto puede leerse como una especie de desarrollo dinámico de la determinación enajenada de la individualidad productiva humana, cuya expresión más simple Marx presenta en la discusión sobre el fetichismo de la mercancía. Como hemos argumentado en otro lado, en ese texto Marx despliega la manera en que la consciencia productiva del individuo privado inconscientemente transpone sus determinaciones

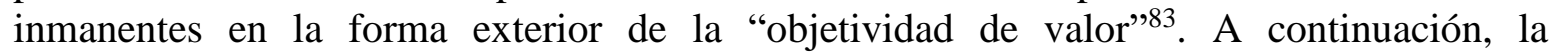
exposición muestra asimismo como la subjetividad misma del productor de mercancías queda determinada como personificación de esas formas objetivadas de mediación social que había engendrado a espaldas de su consciencia y voluntad. Lo que tenemos en este

\footnotetext{
${ }^{82}$ Karl Marx, Contribución a la Crítica de la Economía Política, México, D.F., Siglo XXI, 2008, 128.

${ }^{83}$ Starosta, op. cit., 2015, capítulo 5.
} 
pasaje citado no es sino la exposición de la dinámica transformativa que estructura la constitución de nuevas formas de subjetividad en tanto expresión de la concreción ulterior de la "ley del valor" más allá de sus formas más simples. Se trata, por así decir, de la "ley de la subjetividad privada" que rige el desarrollo de formas más concretas en las que los seres humanos actúan como personificaciones de categorías económicas.

Sin dudas, estas formas más complejas en las que el movimiento del valor adquiere unidad siguen siendo "sólo la expresión objetiva de las mutables relaciones sociales dentro de las cuales los poseedores de mercancías llevan a cabo su proceso metabólico", esto es, su contenido social más simple sigue siendo la relación general de producción entre los seres humanos. Sin embargo, la inversión real de dichas relaciones sociales como atributos de las cosas significa que los seres humanos no pueden controlar conscientemente la transformación de su propia subjetividad (al menos no con las determinaciones desplegadas hasta este punto). Dicha transformación ocurre así a sus espaldas, como resultado del autodesarrollo de las formas enajenadas de objetividad a través de las cuales tiene lugar su proceso de metabolismo social. $\mathrm{Y}$ al autodesarrollarse $\mathrm{y}$ transformarse esas formas objetivadas del ser social, los poseedores de mercancías, "en cuanto vehículos de estas relaciones modificadas [...], adquieren nuevas características económicas", esto es, emergen progresivamente del proceso de circulación general portando "máscaras" diferentes de las que portaban al entrar al mismo.

En el pasaje recién citado Marx identifica las formas de subjetividad que han emergido hasta esa fase particular de su presentación dialéctica. En particular, menciona la figura del simple propietario mercantil, el comprador y vendedor, el atesorador y la gente rica. Sin embargo, la implicancia de esta discusión es que los propietarios de mercancías van a atravesar una serie de "cambios de piel" ulteriores. Así, Marx desarrolla unas páginas después las figuras del deudor y acreedor, haciendo notar también cómo cambian las correspondientes formas ideológicas generales ${ }^{84}$. De la religión como la forma ideológica general correspondiente al atesorador, se pasa a la jurisprudencia como la que corresponde a la forma de subjetividad del acreedor. Por último, "así como el dinero se desarrolla para convertirse en dinero mundial, así el poseedor de mercancías se desarrolla para convertirse en cosmopolita", cuya forma ideológica general no es otra que el "cosmopolitismo [...] como credo de la razón práctica, en contraposición a los prejuicios tradicionales de orden religioso, nacional, y otros, que inhiben el proceso metabólico de la humanidad" 85 .

A nuestro juicio, el punto fundamental de esta discusión es que en estos pasajes de la Contribución de 1859 sale a la luz muy claramente un aspecto fundamental del objeto de la investigación dialéctica de Marx. Concretamente, la misma incluye tanto a las formas de objetividad como a las de subjetividad de la sociedad capitalista. Pero, además, dichas páginas contienen importantes claves metodológicas respecto de cómo debe encararse, desde una perspectiva materialista, la investigación de la génesis de las formas de subjetividad: como mediaciones necesarias del movimiento autonomizado de las formas de objetividad fetichizada asumida por la relación social general en el modo de producción capitalista. Sólo a través de este método es posible fundar las formas de conciencia y

\footnotetext{
${ }^{84}$ Marx, op. cit., 2008, 130-1.
}

${ }^{85}$ Ibid., 143. 
voluntad de modo inmanente al movimiento de las relaciones sociales actuales. Asimismo, y de modo crucial para la temática de este artículo, el corolario de este enfoque es que, si uno quiere ser fiel a un abordaje materialista, este método no debe "aplicarse" solamente a las formas de subjetividad y acción que reproducen la producción de valor (y, a fortiori, de capital), sino que debe incluirse también a la subjetividad revolucionaria. En otras palabras, la forma de sujeto político revolucionario (y, más bien, nuestra propia subjetividad en tanto órgano individual de tal sujeto colectivo y de clase), debe desplegarse de modo inmanente en tanto forma más desarrollada de existencia asumida por el productor de mercancías inicial con el cual comenzó la exposición dialéctica.

Para ponerlo en términos más generales, el fundamento inmanente de la subjetividad revolucionaria no es simple o no mediado. Al contrario, es una "unidad de múltiples determinaciones", lo cual significa que su comprensión científica solo puede resultar de una investigación dialéctica compleja que incluye tanto el movimiento analítico de lo concreto a lo abstracto, como el retorno sintético, mediado, al punto de partida concreto del proceso de conocimiento, esto es, la acción transformadora revolucionaria. El proceso de investigación dialéctica debe entonces aprehender analíticamente todas las formas sociales relevantes del caso, y reproducir sintéticamente las "conexiones internas" que conducen a la constitución de la acción política consciente de los obreros asalariados como clase, en tanto forma necesaria asumida por la transformación revolucionaria del modo de existencia histórico del proceso de vida humano.

Ahora bien, si la "reproducción de lo concreto en el pensamiento" muestra que las determinaciones inmanentes en la forma-mercancía, no portan, en su simplicidad, la necesidad de trascender la producción de valor, su búsqueda debe entonces continuar mediante el despliegue de las formas más concretas en las cuales se desarrolla la relación social general. El proceso de conocimiento debe pasar aún por más mediaciones de forma de devenir plenamente consciente de la necesidad de la propia acción transformadora en la unidad de todas sus determinaciones y, de este modo, sin caer presa de ninguna apariencia. Así, de forma de alcanzar todo su poder transformador, este desarrollo consciente debe alcanzar una forma concreta del propio ser social enajenado que encierre una potencialidad cuya realización: (a) conlleve la abolición misma de la enajenación; y (b) que tenga a nuestra acción transformadora como su forma concreta necesaria. En resumen, la acción revolucionaria debe personificar una determinación concreta de la práctica productora de valor misma, cuya realización, sin embargo, consista precisamente en la abolición de la producción de valor.

En este sentido, lejos de agotar el momento crítico-práctico, la reproducción ideal de la forma-mercancía (en la unidad de su movimiento analítico y sintético), es sólo el primer paso de un proceso de conocimiento dialéctico más amplio a través del cual el sujeto de la transformación revolucionaria descubre el carácter enajenado de su ser social y, en consecuencia, de su propia subjetividad. Sin embargo, como se ha examinado en otro lado, al ser desplegado en su totalidad, este proceso también produce la autoconsciencia de las potencias históricas desarrolladas en esta forma enajenada y, aún más en concreto, de la necesidad de la acción revolucionaria que, como pura personificación de categorías 
económicas (y no como abstractos seres humanos), el sujeto emancipador debe realizar ${ }^{86}$. Ahora bien, no podemos detenernos aquí a discutir dichas determinaciones ulteriores cuya unidad subyace a la constitución de la clase obrera como tal sujeto revolucionario; tarea que, por otra parte, hemos abordado en profundidad en otro texto ${ }^{87}$. Sin embargo, y a modo de conclusión, en el apartado siguiente nos permitimos al menos delinear a trazos gruesos los momentos esenciales del despliegue dialéctico del movimiento de la relación social enajenada capitalista, cuya tendencia histórica deriva en la necesidad de su autoabolición en la forma concreta de la acción transformadora radical del proletariado.

\section{Reflexiones finales: de la mercancía al sujeto revolucionario}

Planteábamos antes que la necesidad de la constitución del sujeto revolucionario debía surgir de modo inmanente a partir del despliegue de las potencias del productor de mercancías con el cuál parte la exposición dialéctica, las cuales someten este último a una sucesión de "cambios de piel". Sin embargo, las transformaciones a las cuáles están sujetos los productores de mercancías no se limitan a las que experimentan como resultado de las determinaciones que desarrolla el proceso de circulación general de mercancías como tal. De hecho, el propio de despliegue de la plenitud de las potencias de la circulación simple de mercancías muestra que la misma trasciende de sí al devenir necesariamente un momento interno de la circulación del capital.

En la forma de capital, la relación social general cosificada en la forma de la "objetividad de valor" ya no se afirma tan solo como mediadora del proceso de metabolismo entre los productores privados e independientes. Este fetichismo e inversión se desarrollan aún más, al convertirse el capital en el sujeto enajenado mismo de la unidad del proceso de vida social. Todos los momentos del metabolismo humano pasan así a convertirse en atributos del "ciclo vital" del capital, el cual tiene a la autovalorización o automovimiento en progresión cuantitativa, como única determinación cualitativa general. La producción inmediata de la vida humana deja así de constituir el contenido del movimiento de reproducción social para devenir el resultado inconsciente de la producción incesante de plusvalor.

Al desarrollarse la relación social general en un proceso de producción de plusvalor, los poseedores de mercancías que entran y emergen del mismo experimentan nuevas transformaciones y adquieren "nuevas características económicas". En primer lugar, se diferencian, respectivamente, en personificaciones del dinero-como-capital y la mercancía fuerza de trabajo. En segundo lugar, dichas personificaciones individuales devienen personificaciones colectivas al constituirse necesariamente como clases sociales, en tanto el antagonismo inherente a la compra-venta de la fuerza de trabajo por su valor sólo puede resolverse al trascender la mera relación individual entre comprador y vendedor, esto es, tomando la forma concreta de la lucha de clases ${ }^{88}$. Esta última se constituye entonces en la

\footnotetext{
${ }^{86}$ Iñigo Carrera, op. cit., 2013, capítulo 1.

${ }^{87}$ Starosta, op. cit., 2015, capítulos 8 y 9.

${ }^{88}$ Guido Starosta y Gastón Caligaris, Trabajo, Valor y Capital. De la Crítica Marxiana de la Economía Política al Capitalismo Contemporáneo, Bernal, Universidad Nacional de Quilmes, 2017 (en prensa), capítulo 5.
} 
relación social directa más general entre personificaciones colectivas de mercancías, a través de la cual se establece la unidad esencialmente indirecta de la producción social subordinada a la autovalorización del capital. Sin embargo, por más ineludible y 'endémico' que sea este antagonismo, y en claro contraste con el planteo del Marxismo abierto reseñado más arriba, en esta determinación simple, esto es, como expresión de la subsunción formal del trabajo en el capital, la lucha de clases sólo existe como forma concreta necesaria de la reproducción de la enajenación capitalista y no de su superación.

Son en realidad las determinaciones de la subsunción real del trabajo en el capital, y en particular de la forma más desarrollada de producción de plusvalía relativa como gran industria, las que portan las potencias que se expresan en la forma específicamente emancipatoria de la lucha de clases. Esto es así en tanto la producción de plusvalía relativa somete al proceso directo de producción de la vida humana a una incesante revolución en su misma materialidad. Como Marx muestra en El capital y en los Grundrisse, a través de esta mutación constante en las condiciones materiales del trabajo social, el capital transforma, contradictoria pero progresivamente, la subjetividad productiva de los obreros asalariados de acuerdo a una tendencia determinada: los mismos devienen trabajadores universales, esto es, órganos de un cuerpo productivo directamente colectivo capaces de regir con plena autoconsciencia su participación individual en el proceso de metabolismo social. Puesto en otros términos, los miembros del obrero colectivo se constituyen en sujetos productivos que son completa y objetivamente conscientes de las determinaciones sociales de sus potencias y actividad individuales. Pero, como es evidente, esta forma de la subjetividad humana necesariamente choca con una forma social capitalista que, como tal, produce a los seres humanos como individuos privados e independientes quienes, en consecuencia, ven a su interdependencia social general y su desarrollo histórico como una potencia ajena y hostil portada por el producto del trabajo social. La determinación de las formas materiales del proceso de trabajo como portadoras de relaciones sociales objetivadas ya no puede, por tanto, mediar la reproducción de la vida humana. La acumulación de capital debe, en consecuencia, llegar a su fin y dar paso a la libre asociación de los individuos. Es este el contenido material inmanente del desarrollo de la relación social general que se expresa necesariamente en la forma de la subjetividad política revolucionaria de la clase obrera.

Así, es la necesidad histórica determinada de la plena universalidad desarrollada y socializada de la subjetividad productiva de los trabajadores, más allá de su "corteza" capitalista pero generada como una determinación inmanente del movimiento enajenado del propio capital, lo que se realiza bajo la forma concreta de la revolución comunista. Esto implica que la consciencia política revolucionaria de la clase obrera sólo puede ser expresión concreta de su consciencia productiva ${ }^{89}$. Lo que la acción política del

\footnotetext{
${ }^{89}$ También implica que la acción revolucionaria es expresión de una subjetividad enajenada. En otras palabras, la abolición del capital no es producto de una acción política autodeterminada o abstractamente libre, sino que es una acción que los trabajadores están compelidos a realizar como personificaciones de las leyes enajenadas del movimiento del capital mismo. Lo que separa a la acción política superadora del capital de las formas de la lucha de clases que reproducen el capital es su determinación específica como acción colectiva que es plenamente consciente de su carácter enajenado, esto es, de estar personificando una necesidad del capital. Sin embargo, al tomar consciencia de su determinación como modo de existencia del capital, los obreros revolucionarios también descubren la tarea histórica de la que, como
} 
proletariado realiza, esto es, su contenido, es la transformación de la materialidad de las fuerzas productivas del individuo humano $\mathrm{y}$, en consecuencia, de sus formas sociales de organización y desarrollo. En otros términos, se trata de una mutación material del proceso de producción de la vida humana, que toma forma concreta mediante una transformación de sus formas sociales, la cual, a su vez, se realiza mediante una acción política consciente o, dicho con todas las letras, mediante una revolución. Así, la cuestión aquí no es tratar de encontrar las "condiciones objetivas" externas que disparan o facilitan el desarrollo de una acción política autodeterminada. En cambio, lo que está en juego aquí es el desarrollo del conocimiento consciente del contenido y la forma de la necesidad de abolir la forma capital.

En este sentido, y para concluir, nótese que lo que aborda el proceso de conocimiento de la ciencia como crítica práctica no son las circunstancias externas que constreñirían o constituirían el contexto social para una acción que, si bien sujeta estos condicionamientos, sería en y por sí misma autodeterminada. Más bien, se trata de la autoconsciencia respecto de las determinaciones portadas de modo inmanente en nuestra acción transformadora enajenada. Así, la ciencia social dialéctica, en tanto crítica práctica, no mira "fuera" de la acción con el fin de da cuenta de las circunstancias que limitan su afirmación, sino que, al penetrar las apariencias inmediatas que tal acción presenta, se sitúa "dentro" de la misma. Por ello, en la ciencia como crítica práctica el terreno de la materialidad de la práctica humana concreta nunca se abandona. Y sólo en virtud de su forma dialéctica, que involucra tanto el momento analítico como el sintético, y que tiene como objeto la unidad de las formas de objetividad y subjetividad asumidas por el ser social, es que la crítica de la economía política queda determinada como la organización plenamente consciente de la práctica humana en el capitalismo y, en tal condición, como la ciencia revolucionaria de la clase obrera ${ }^{90}$.

\section{Bibliografía}

Theodor Adorno, Dialéctica Negativa, Madrid, Taurus, 1992 [1966].

Shlomo Avineri, The Social and Political Thought of Karl Marx, Cambridge, Cambridge University Press, 1993 [1968].

Hans-Georg Backhaus, "On the Dialectics of the Value-Form”, Thesis Eleven, 1, 1980, 99-120.

Hans-Georg Backhaus, "Between Philosophy and Science: Marxian Social Economy as Critical Theory", en Open Marxism, Volume 1: Dialectics and History, editado por Werner Bonefeld, Richard Gunn et al., London, Pluto Press, 1992, 54-92.

Hans-Georg Backhaus, "Some Aspects of Marx's Concept of Critique in the Context of his Economic-Philosophical Theory", en Human Dignity: Social Autonomy and the Critique of Capitalism, editado por Werner Bonefeld y Kosmas Psychopedis, Aldershot, Ashgate, 2005, 13-30.

individuos plenamente conscientes, aunque enajenados, deben encargarse: la superación del capital mediante la producción de la organización comunista de la vida social. La subjetividad revolucionaria, en consecuencia, se organiza como una acción política enajenada que en el curso de su propio desarrollo se libera de su propia enajenación.

${ }^{90}$ Iñigo Carrera, op. cit., 2007, 7-8. 
Hans-Georg Backhaus, Dialettica della Forma di Valore. Elementi critici per la riconstruzione della teoría marxiana del valore, Roma, Editori Riuniti, 2009.

Riccardo Bellofiore y Tommaso Redolfi Riva, "The Neue Marx-Lektüre. Putting the critique of political economy back into the critique of society", Radical Philosophy, 189, 2015, 24-36.

Werner Bonefeld, "Social Constitution and the Form of the Capitalist State", in Open Marxism, Volume I: Dialectics and History, edited by Werner Bonefeld, Richard Gunn et al., London, Pluto Press, 1992, 93-132.

Werner Bonefeld, The Recomposition of the British State During the 1980s, Aldershot: Dartmouth, 1993.

Werner Bonefeld, "Capital as Subject and the Existence of Labour", en Open Marxism, Volume 3: Emancipating Marx, editado por Werner Bonefeld, Richard Gunn et al., London, Pluto Press, 1995, 182-212.

Werner Bonefeld, "Review of Hans-Georg Backhaus's 'Dialektik der Wertform: Untersuchungen zur marxschen Ökonomiekritik",, Capital and Class, 22(3), 1998, 158-61.

Werner Bonefeld, 'Kapital and Its Subtitle: A Note on the Meaning of Critique', Capital and Class, 25(3), 2001, 53-63.

Werner Bonefeld, "History and Human Emancipation: Struggle, Uncertainty and Openness", Critique, 38(1), 2010, 61-73.

Werner Bonefeld, "Primitive Accumulation and Capitalist Accumulation: Notes on Social Constitution and Expropriation”, Science and Society, 75(3), 2011, 379-99.

Werner Bonefeld, "Negative Dialectics in Miserable Times: Notes on Adorno and Social Praxis", Journal of Classical Sociology, 12(1), 2012, 122-34.

Werner Bonefeld, Critical Theory and the Critique of Political Economy, London, Bloomsbury, 2014.

Werner, Bonefeld, Richard Gunn y Kosmas Psychopedis (eds.), Open Marxism, vol. 1: Dialectics and History. London, Pluto Press, 1992a.

Werner, Bonefeld, Richard Gunn y Kosmas Psychopedis (eds.), Open Marxism - vol. 2: Theory and Practice, London, Pluto Press, 1992b.

Werner, Bonefeld, John Holloway y Kosmas Psychopedis (eds.), Open Marxism - vol. 3: Emancipating Marx, London, Pluto Press, 1995.

Werner Bonefeld y John Holloway (eds.), Post-Fordism and Social Form: A Marxist Debate on the Post-Fordist State, Basingstoke, Macmillan, 1991.

Bonefeld, Werner y Psychopedis, K. (eds.), Human Dignity: Social Autonomy and the Critique of Capitalism. Aldershot: Ashgate Publishing Ltd, 2005.

Gastón Caligaris y Guido Starosta, "La crítica marxiana de la dialéctica hegeliana", Praxis Filosófica, 41, julio-diciembre, 2015, 81-112.

Harry Cleaver, Reading Capital Politically, Brighton, Harverster Press, 1979.

Harry Cleaver, "The Inversion of Class Perspective in Marxian Theory: From Valorisation to SelfValorisation", en Open Marxism, Volume II: Theory and Practice, editado por Werner Bonefeld, Richard Gunn y Kosmas Psychopedis, London, Pluto Press, 1992, 106-44.

Massimo De Angelis, The Beginning of History: Value Struggles and Global Capital, London, Pluto Press, 2007. 
Ingo Elbe, "Between Marx, Marxism and Marxisms. Ways of Reading Marx's Theory", Viewpoint Magazine - Investigations in Contemporary Politics, www.viewpointmag.com, 21 de octubre de 2013, consultado 31 de agosto de 2017.

Endnotes, "Communisation and Value-Form Theory", Endnotes, 2, 2010, 68-105.

Richard Gunn, "Against Historical Materialism: Marxism as a First-Order Discourse", en Open Marxism, Volume II: Theory and Practice, editado por Werner Bonefeld, Richard Gunn y Kosmas Psycholedis, London, Pluto Press, 1992b, 1-45.

Richard Gunn y Adrian Wilding, "Holloway, La Boétie, Hegel”, Journal of Classical Sociology, 12(2), 2012, 173-90.

Richard Gunn y Adrian Wilding, "Recognition Contradicted", South Atlantic Quarterly, 113(2), 2014, 339-52.

Michael Heinrich, Crítica de la Economía Política. Una introducción a El Capital de Marx, Madrid, Escobar y Mayo, 2008.

Michael Heinrich, ¿Cómo leer El Capital de Marx? Indicaciones de lectura y comentario del comienzo de El Capital, Madrid, Escobar y Mayo, 2011.

Jan Hoff, Marx Worlwide: On the Development of the International Discourse on Marx since 1965, Leiden, Brill, 2016.

John Holloway, Change the World without Taking Power: The Meaning of Revolution Today, London, Pluto Press, 2002.

John Holloway, Crack Capitalism, London, Pluto Press, 2010.

Juan Iñigo Carrera, El Conocimiento Dialéctico, Buenos Aires, Centro para la Investigación como Crítica Práctica, 1992.

Juan Iñigo Carrera, Conocer el capital hoy. Usar críticamente El Capital, Buenos Aires, Imago Mundi, 2007.

Juan Iñigo Carrera, El Capital: Razón Histórica, Sujeto Revolucionario y Conciencia, Buenos Aires, Ediciones Cooperativas, 2013 [2003].

Karl Marx, Elementos Fundamentales para la Crítica de la Economía Política (Grundrisse), México, D.F., Siglo XXI, 1989 [1857-8].

Karl Marx, El Capital. Crítica de la Economía Política, Tomo I, México, D.F., Siglo XXI, 1999 [1867].

Karl Marx, Contribución a la Crítica de la Economía Política, México, D.F., Siglo XXI, 2008 [1859].

Helmut Reichelt, "From the Frankfurt School to Value-Form Analysis", Thesis Eleven, 4, 1982, 166-9.

Helmut Reichelt, "Why Did Marx Conceal His Dialectical Method?", en Open Marxism, Volume 3: Emancipating Marx, editado por Werner Bonefeld, Richard Gunn et al., London, Pluto Press, 1995, 40-83.

Helmut Reichelt, "Social Reality as Appearance: Some Notes on Marx's Conception of Reality", en Human Dignity: Social Autonomy and the Critique of Capitalism, editado por Werner Bonefeld y Kosmas Psychopedis Aldershot, Ashgate, 2005, 31-68.

Helmut Reichelt, "Marx's Critique of Economic Categories: Reflections on the Problem of Validity in the Dialectical Method of Presentation in Capital", Historical Materialism, 15(4), 2007, 3-52. 
Helmut Reichelt, Sobre a Estrutura Lógica do Conceito de Capital em Karl Marx, Campinas, Editora Unicamp, 2009.

Felton Shortall, The Incomplete Marx, Aldershot, Avebury, 1994.

Guido Starosta, "The Commodity-Form and the Dialectical Method", Science \& Society, 72(3), 2008, 295-318.

Guido Starosta, Marx's Capital, Method and Revolutionary Subjectivity, Leiden, Brill, 2015.

Guido Starosta y Gastón Caligaris, Trabajo, Valor y Capital. De la Crítica Marxiana de la Economía Política al Capitalismo Contemporáneo, Bernal, Universidad Nacional de Quilmes, 2017 (en prensa). 